Reinmöller, Markus; Ulbrich, Angela; Ikari, Tomonori; Preiß, Julia; Höfft, Oliver; Endres, Frank; Krischok, Stefan; Beenken, Wichard J. D.:

\title{
Theoretical reconstruction and elementwise analysis of photoelectron spectra for imidazolium-based ionic liquids
}

URN: $\quad$ urn:nbn:de:gbv:ilm1-2014210147

Published OpenAccess: September 2014

Original published in:

Physical chemistry, chemical physics : PCCP ; a journal of European chemical societies. - Cambridge : RSC Publ (ISSN 1463-9084). - 13 (2011) 43, S. 1952619533.

DOI: $\quad 10.1039 / C 1 C P 22152 C$

URL: $\quad$ http://dx.doi.org/10.1039/C1CP22152C

[Visited: 2014-09-09]

„Im Rahmen der hochschulweiten Open-Access-Strategie für die Zweitveröffentlichung identifiziert durch die Universitätsbibliothek IImenau."

"Within the academic Open Access Strategy identified for deposition by Ilmenau University Library."

"Dieser Beitrag ist mit Zustimmung des Rechteinhabers aufgrund einer (DFG-geförderten) Allianz- bzw. Nationallizenz frei zugänglich."

"This publication is with permission of the rights owner freely accessible due to an Alliance licence and a national licence (funded by the DFG, German Research Foundation) respectively."

\section{DFG}

Nationallizenzen 


\title{
Theoretical reconstruction and elementwise analysis of photoelectron spectra for imidazolium-based ionic liquids
}

\author{
Markus Reinmöller, ${ }^{a}$ Angela Ulbrich, ${ }^{a}$ Tomonori Ikari, ${ }^{b}$ Julia Preiß, ${ }^{a}$ Oliver Höfft, ${ }^{c}$ \\ Frank Endres, ${ }^{c}$ Stefan Krischok ${ }^{a}$ and Wichard J. D. Beenken ${ }^{* a}$
}

Received 30th June 2011, Accepted 8th September 2011

DOI: $10.1039 / \mathrm{c} 1 \mathrm{cp} 22152 \mathrm{c}$

We have recently measured core level and valence band XPS, UPS, and MIES spectra of two room temperature ionic liquids composed of bis(trifluoromethylsulfonyl)imide anions $\left(\left[\mathrm{Tf}_{2} \mathrm{~N}\right]^{-}\right)$ and either 1-ethyl-3-methyl-imidazolium $\left([\mathrm{EMIm}]^{+}\right)$or 1-octyl-3-methyl-imidazolium cations $\left([\mathrm{OMIm}]^{+}\right)$. [T. Ikari, A. Keppler, M. Reinmöller, W. J. D. Beenken, S. Krischok, M. Marschewski, W. Maus-Friedrichs, O. Höfft and F. Endres, e-J. Surf. Sci. Nanotechnol., $2010,8,241$.] In the present work we analyze these spectra by means of partial density of states (pDOS) as calculated from a single ion pair of the respective ionic liquid using density functional theory (DFT). Subsequently we reconstruct the XPS and UPS spectra by considering photoemission cross sections and analyze the MIES spectra by pDOS, which provides us decisive hints to the ionic liquid surface structure.

\section{Introduction}

The surface structure of room temperature ionic liquids determines a multitude of their properties, ${ }^{2-6}$ opening a wide

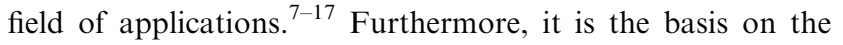
way to understanding interfaces between ionic liquids and other materials, which could be non-polar, polar or ionic. The knowledge of the surface structure of ionic liquids concerns also their application in tribology, ${ }^{17-19}$ electrochemistry, ${ }^{12,20-22}$ and catalysis. ${ }^{7,20,23,24}$

The first step towards an understanding of the ionic liquid surfaces under vacuum is the identification of their chemical composition (e.g. an enrichment of one ion may occur). This has been investigated with various UHV techniques, e.g., X-ray photoelectron spectroscopy (XPS), ${ }^{1,25-30}$ soft X-ray emission spectroscopy, ${ }^{31,32}$ secondary ion mass spectroscopy, ${ }^{33}$ scanning atom probe, ${ }^{34}$ high resolution Rutherford backscattering spectroscopy (HRBS). ${ }^{35,36}$ Detailed information about the surface structure has also been obtained by other surface sensitive methods, e.g. sum frequency generation (SFG), which features an analysis of the orientation of components of the ions present at the surface. ${ }^{4,6,37}$ A collection of ionic liquids, which consists of bis(trifluoromethylsulfonyl)imide anions $\left(\left[\mathrm{Tf}_{2} \mathrm{~N}\right]^{-}\right)$ and various 1-alkyl-3-methyl-imidazolium cations $\left([\mathrm{EMIm}]^{+}\right.$,

${ }^{a}$ Institute of Physics and Institute of Micro- and Nanotechnologies, Ilmenau University of Technology, P.O. Box 100565 , 98684 Ilmenau, Germany.E-mail: wichard.beenken@tu-ilmenau.de

${ }^{b}$ Department of Electrical Engineering, Ube National College of Technology, 2-14-1 Tokiwadai, Ube, Yamaguchi 755-8555, Japan

${ }^{c}$ Institute of Particle Technology, Clausthal University of Technology, Arnold-Sommerfeld-Str. 6, D-38678 Clausthal-Zellerfeld, Germany
$\left.[\mathrm{BMIm}]^{+},[\mathrm{HMIm}]^{+},[\mathrm{OMIm}]^{+}\right)$, has been intensively studied by many methods, ${ }^{38}$ inter alia angle-resolved XPS, ${ }^{25,28} \mathrm{UPS}^{8}$ $\mathrm{SFG}^{37}$ and HRBS. ${ }^{35,36}$ It has been shown that most probably the longer alkyl-chains (e.g. octyl for [OMIm] Tf $f_{2} \mathrm{~N}$ ) of the cation stick out of the ionic liquid surface. However, using the extremely surface sensitive metastable induced electron spectroscopy (MIES) ${ }^{1}$ we have recently also found significant hints that the alkyl-chains in [OMIm] $\mathrm{Tf}_{2} \mathrm{~N}$ do not completely cover the surface, but the $\left[\mathrm{Tf}_{2} \mathrm{~N}\right]^{-}$anion may be still present there. The former result has been supported by parallel MIES studies of T. Iwahashi et al. ${ }^{39}$ Molecular dynamics simulations of the interface between imidazolium-based ionic liquids and vacuum/air by A. S. Pensado et al., ${ }^{40}$ T. Yan et al., ${ }^{41}$ and C. D. Wick et $a l^{42}$ have found the alkyl-chain sticking out of the surface and have found the anion, e.g. $\left[\mathrm{Tf}_{2} \mathrm{~N}\right]^{-}$in $[\mathrm{HMIm}] \mathrm{Tf}_{2} \mathrm{~N}$ (see ref. 40), at the interface as well. In our previous work ${ }^{30}$ it has been displayed that the density of states from DFT calculations of a single ion pair is suitable for a comparison with photoelectron spectra as well as for the visualization of molecular orbitals near the valence band edge. Furthermore, ionic liquids containing large anions like $\left[\mathrm{Tf}_{2} \mathrm{~N}\right]^{-}$ have shown a less ordered surface than smaller ones. ${ }^{26}$ Consequently, a single ion pair seems to be better applicable for larger anions than for smaller ones, which might require another approach and a single ion pair costs only adequate calculation times. For a more detailed analysis - in particular to address spectral features of certain molecular groups - it is necessary to analyze the XPS, UPS and MIES spectra by comparison with the pDOS as obtained from quantum-chemical calculations and projected to single atoms, or even better to reconstruct the photoelectron spectra. In what follows we will show such 


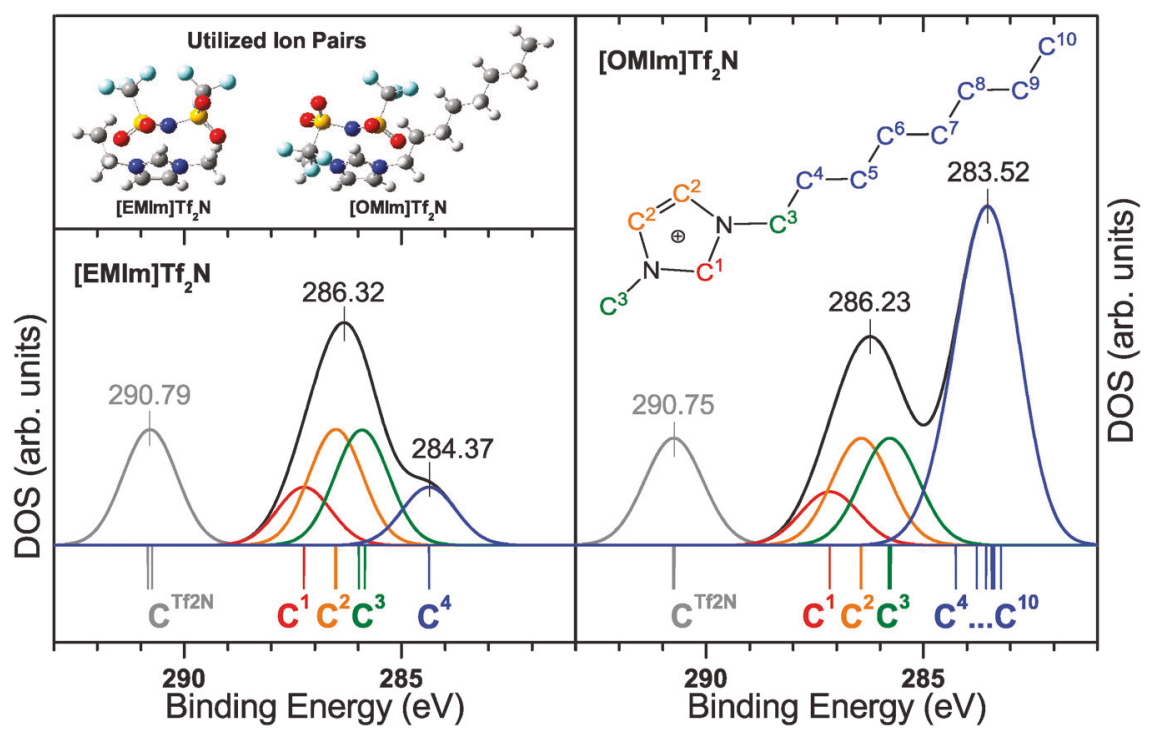

Fig. 1 Density of states (DOS) for C1s core levels from DFT calculations with its composition by contributions from the carbon atoms at different positions (affiliation of $\mathrm{C}^{1-10}$, see the inset) and the respectively utilized ion pairs for [EMIm] $\mathrm{Tf}_{2} \mathrm{~N}$ and $[\mathrm{OMIm}] \mathrm{Tf}{ }_{2} \mathrm{~N}$ (top left). For exact values and experimental data, see Table 1.

reconstructions for XPS and UPS spectra of two typical ionic liquids, [EMIm] $\mathrm{Tf}_{2} \mathrm{~N}$ and $[\mathrm{OMIm}] \mathrm{Tf}_{2} \mathrm{~N}$. Furthermore, we will show that the pDOS is extremely helpful to interpret specific features of MIES spectra.

\section{Calculation method}

For the determination of the pDOS, we have applied DFT using Becke's hybrid functional B3-LYP together with the $6-31 \mathrm{G}^{* *}$ basis set ${ }^{43-47}$ on single ion pairs of [EMIm] $\mathrm{Tf}_{2} \mathrm{~N}$ and $[\mathrm{OMIm}] \mathrm{Tf}_{2} \mathrm{~N}$, respectively. By comparison of the reconstructed spectra with those obtained from two-dimensional crystal structures of $[\mathrm{EMIm}] \mathrm{Tf}_{2} \mathrm{~N}$ we have verified that the effects of the neglected interaction of one ion pair with others (bulk state) have only a minor influence. Moreover, the DOS obtained from single ion pair calculations has displayed a very good agreement with the experimental data for the gas phase as well as the liquid state as shown by D. Strasser et al. ${ }^{48}$ Direct comparison of binding energies from the gas phase measurements ${ }^{48}$ and the calculated ion pair DOS is not expedient, since the absolute value of calculated binding energies depends on the applied basis set and functional ( $c f$. ref. 49). The general shape of the DOS, i.e. the relative values of binding energies, seems to be robust against changes of the basis set. For this reason we have performed a global calibration of the calculated DOS and the reconstructed spectra as described in detail below. The ion pair structures have been optimized with the same method used elsewhere. ${ }^{30}$ Different ion pair configurations have minor influence on our reconstructed valence band spectra, since the spectra are more depending on the applied cross sections for photoelectron emission than on the exact binding energy position or relative geometry between the two ions. This is also the reason why we could apply a relatively simple hybrid-functional (B3-LYP) without any dispersion correction, which of course may have influenced the interaction mainly between the ion pairs. For the details of a dispersion correction for ionic liquids, see ref. 50 and 51 . To prove the assumption of minor influence of the ion pair geometry on the reconstructed XPS valence band spectra we have calculated those for 18 ion pairs from [EMIm] $\mathrm{Tf}_{2} \mathrm{~N}$. All of them exhibit an energetically favored position of the $\left[\mathrm{Tf}_{2} \mathrm{~N}\right]^{-}$anion in the vicinity of the ring-carbon, which is placed between the two imidazolium nitrogens of the $[\text { EMIm }]^{+}$cation. S. B. C. Lehmann et al. ${ }^{51}$ have identified in their quantum-chemical studies using ion pairs that the connection between cations and anions is predominantly established via the most acidic hydrogen bond to this ringcarbon and either the nitrogen or the oxygen of the $\left[\mathrm{Tf}_{2} \mathrm{~N}\right]^{-}$ anion. Within the large number of our ion pairs we have ascertained that the single point energy varies about $\Delta E=171 \mathrm{meV}$. The differences between the resulting XPS spectra of these 18 ion pairs are in the range of the noise of the experimental spectrum. Similarly, T. Cremer et al. ${ }^{27}$ have shown that different conformers of the ion pair do not strongly influence the highest occupied molecular orbitals.

For our analysis we had to choose two ion pairs, one from each ionic liquid. Both ion pairs exhibit nearly the same relative geometry, where the nitrogen of the $\left[\mathrm{Tf}_{2} \mathrm{~N}\right]^{-}$anion is used to form the connection to the mentioned most acidic hydrogen of the cation. A change in the preferred conformer of the $\left[\mathrm{Tf}_{2} \mathrm{~N}\right]^{-}$anion at the surface depending on the alkylchain length of the cation was recently found by K. Nakajima et $a l .{ }^{36}$ This fact was considered by the choice of an ion pair with a $s y n$-conformer of the anion for [EMIm] $\mathrm{Tf}_{2} \mathrm{~N}$ and one with the respective anti-conformer is chosen for [OMIm] $\mathrm{Tf}_{2} \mathrm{~N}$ (see the displayed structure of the two utilized ion pairs in Fig. 1). The utilized ion pair has the lowest single point energy of all calculated pairs of [OMIm] $\mathrm{Tf}_{2} \mathrm{~N}$ and it is one of the best for [EMIm]Tf ${ }_{2}$ N. Ab initio calculations for ion pairs by K. Fujii et al. ${ }^{52}$ have shown that the syn-conformer of the anion exhibits a slightly higher energy than the anti-conformer. This energetic order is also present in our calculations. However, we found no significant differences between the reconstructed spectra using a syn- or an anti-conformer of the $\left[\mathrm{Tf}_{2} \mathrm{~N}\right]^{-}$anion. Furthermore, there occurs a rapid change between these two 
conformers of the $\left[\mathrm{Tf}_{2} \mathrm{~N}\right]^{-}$anion in the liquid state described by E. Bodo et al. ${ }^{53}$

Subsequently, for the relaxed single ion pair structure we have determined the molecular Kohn-Sham eigenenergies $\varepsilon_{i}$ and the eigenvectors $c_{i \mu}$ in the corresponding LCAO. The eigenenergies give us already the total DOS as $\rho(\varepsilon)=$ $\sum \delta\left(\varepsilon-\varepsilon_{i}\right)$, whereas for the pDOS the eigenvectors $c_{i \mu}$ of the LCAO provide us with the respective contribution of each atomic orbital $|\mu\rangle$ to the DOS, which is given by $\rho_{\mu}(\varepsilon)=\sum_{i} c_{i \mu}^{2} \delta\left(\varepsilon-\varepsilon_{i}\right)$. Added up over all atomic orbitals $|\mu\rangle$ belonging to the same atom, this results in the pDOS. Furthermore, it allows us also to reconstruct XPS and UPS spectra, respectively. For this purpose we have weighted the calculated contributions $\rho_{\mu}(\varepsilon)$ with the corresponding differential cross section $\mathrm{d} \sigma_{\mu} / \mathrm{d} \Omega\left(E_{\text {photon }}\right)$ of photoelectron emission as tabulated for each element, kind of orbital, used photon energy $\left(E_{\text {photon }}\right)$, and given angular distribution $(\Omega)$ in the literature. ${ }^{54,55}$ Asymmetry (characterized by the asymmetry parameter $\beta$ ) is included in the reconstruction by means of an angular asymmetry factor $L_{\mu}(\gamma)$ for nonpolarized light to be multiplied with the initial differential photoelectron cross section: ${ }^{56} L_{\mu}(\gamma)=1+\frac{\beta_{\mu}}{2}\left[\frac{3}{2} \sin ^{2} \gamma-1\right]$, where $\gamma$ is the angle between the radiation source and the detector (photoelectron emission direction), and $\gamma$ exhibits the values of $80^{\circ}$ for XPS and $42.5^{\circ}$ for UPS (He II). For the UPS spectra the spectrum calculated for the He II $\alpha$-line is accompanied by the He II $\beta$-line, which is simply a duplicate of the He II $\alpha$-line spectrum shifted by approximately $7.56 \mathrm{eV}$ and of typically $4 \%$ of the $\alpha$-line intensity in our experiment. Finally, we have convoluted the resulting stick-spectra with a Gaussian of $0.65 \mathrm{eV}$ width.

All reconstructed spectra have to be calibrated to the experimental spectra. Therefore we introduce one scaling factor (i) and two shifts (ii, iii): (i) due to a known systematic error of DFT calculations (see below and ref. 49) the molecular eigenenergies $\varepsilon_{i}$ have to be corrected by a multiplicative scaling factor, in order to fit the experimentally observed energy differences between the core levels and the valence band. The experimentally observed energetic distance of the $\mathrm{N}^{\mathrm{Tf} 2 \mathrm{~N}} 1 \mathrm{~s}$ peak and the highest valence band peak at around $11 \mathrm{eV}$ (which is also dominated by the $\left[\mathrm{Tf}_{2} \mathrm{~N}\right]^{-}$anion) in the XPS spectra is obtained by a scaling factor of 1.02838. This factor is used for all reconstructed spectra and the pDOS.

(ii) In the next step we shifted the spectral contributions of the cation $\left([\mathrm{EMIm}]^{+}\right.$or $[\mathrm{OMIm}]^{+}$) relatively to the anion $\left[\mathrm{Tf}_{2} \mathrm{~N}\right]^{-}$in order to compensate the overestimated peak splitting in the N1s and C1s core levels. These differences between anion and cation contributions may be caused by a varying Madelung energy as previously suggested by D. Yoshimura et al., ${ }^{8}$ see below. Based on the difference between experimental and reconstructed N1s core levels of both ions we applied a shift of $-1.1 \mathrm{eV}$. A detailed discussion for this shift is performed in the results part. (iii) We have to shift the total binding energy of the reconstructed spectra due to the following reasons: first the vacuum energy of the calculation usually does not match the Fermi energy, which is the reference for experimental XPS and UPS, and secondly the experimental spectra may be affected by charging due to photoelectron emission $^{57,58}$ (charging shifts the binding energy positions for all states about the same value ${ }^{57}$ ). For best agreement of our reconstructed XPS core levels and valence bands with experiment the respective shifts in the binding energy are $-1.36 \mathrm{eV}$ for [EMIm] $\mathrm{Tf}_{2} \mathrm{~N}$ and $-1.39 \mathrm{eV}$ for $[\mathrm{OMIm}] \mathrm{Tf}_{2} \mathrm{~N}$. The shifts used for UPS (He II) are $-1.26 \mathrm{eV}$ for [EMIm] $\mathrm{Tf}_{2} \mathrm{~N}$ and $-1.29 \mathrm{eV}$ for $[\mathrm{OMIm}] \mathrm{Tf}_{2} \mathrm{~N}$. For MIES several pDOS contributions related to $[\mathrm{OMIm}] \mathrm{Tf}_{2} \mathrm{~N}$ have been utilized. These were shifted by the same value of $-1.29 \mathrm{eV}$ as used for UPS. All shifts are already included in the reconstructed valence band spectra for XPS and UPS and the pDOS for MIES presented in the figures.

We are aware that the actual meaning of Kohn-Sham orbitals and their energies has been subject to a long-standing discussion ( $c f$. ref. 59). Though it has been shown quite early that for exact density functionals the energy of the highest occupied Kohn-Sham orbital (HOMO) corresponds to the ionization potential, ${ }^{60-62}$ this aspect of the Kohn-Sham orbital energies had to be further scrutinized. ${ }^{63-66} \mathrm{C}$. G. Zhan et al. ${ }^{67}$ examined the possibility to use Kohn-Sham orbital energies calculated by common functional - in particular the hybrid functional B3-LYP used in the present work - not only for determining ionization potentials, but also electron affinities and electronic excitation energies. They found a linear correlation between the calculated Kohn-Sham energies and the experimentally determined values of ionization potentials. This turns out to be also valid for core-ionization energies ${ }^{68}$ and valence-orbitals, where the energy-correction follows that of the HOMO ${ }^{69}$ The Kohn-Sham energies, if calibrated in the way described above, may be applied for calculating ionization potentials. This is similar to Koopman's theorem ${ }^{70}$ in HartreeFock theory where due to a systematic underestimating of ionization energies a calibration to experimental values is needed as well. ${ }^{69}$ An alternative method for the calculation of photoelectron spectra is given by L. Sištík et al., ${ }^{71}$ in which the effects of excited states (TDDFT) and the resulting single occupied molecular orbitals are considered. This calculation method, however, is much more complex than our technique.

Important to mention is the relevant depth of information for the performed XPS, UPS and MIES measurements. According to Roberts et al. ${ }^{72}$ the sampling depth, which is given by the inelastic mean free path length (IMPF) of emitted electrons as $3 \cdot I M F P \cdot \cos \Theta$, is around $6 \mathrm{~nm}\left(E_{\mathrm{kin}}=1000-1500 \mathrm{eV}, h v=\right.$ $1486.7 \mathrm{eV}$, emission angle $\Theta=53^{\circ}$ ) in the performed XPS measurements, while for the UPS measurements using He II radiation $(h v=40.8 \mathrm{eV}$ ) the IMFP is close to its minimum providing best surface sensitivity in photoelectron spectroscopy measurements. ${ }^{72,73}$ In MIES measurements only those molecular orbitals are probed that point out of the surface, since deexcitation of the metastable helium occurs around $0.2 \mathrm{~nm}$ in front of the surface. ${ }^{74}$

\section{Results and discussions}

\section{XPS core level spectra}

In Table 1 the calculated energies of core levels of nitrogen (N1s) and carbon (C1s) are shown and compared to the data from experimental XPS spectra. ${ }^{1}$ For the N1s core level we found three states: one attributed to the single nitrogen in the $\left[\mathrm{Tf}_{2} \mathrm{~N}\right]^{-}$anion and two corresponding to the two nitrogen 
Table $1 \mathrm{~N} 1 \mathrm{~s}$ and $\mathrm{C} 1 \mathrm{~s}$ energies of [EMIm]Tf ${ }_{2} \mathrm{~N}$ and $[\mathrm{OMIm}] \mathrm{Tf}_{2} \mathrm{~N}$ in $\mathrm{eV}$ as calculated by DFT with the B3-LYP functional and 6-31G** basis set, and corrected by a scaling factor of 1.02838 , and respective shifts of $-1.36 \mathrm{eV}$ for [EMIm] $\mathrm{Tf}_{2} \mathrm{~N}$ and $-1.39 \mathrm{eV}$ for [OMIm] $\mathrm{Tf}_{2} \mathrm{~N}$ to match the experimental N1s level of $\mathrm{Tf}_{2} \mathrm{~N}(\#)$. Experimental values are taken from ref. 1. The energies of the isolated $[\mathrm{OMIm}]^{+}$cation have been normalized by the same scaling factor as used for the ion pairs but shifted approximately by $-4.90 \mathrm{eV}$ in order to match the experimental N1s level $(\$)$ for $[\mathrm{OMIm}] \mathrm{Tf}_{2} \mathrm{~N}$. For the affiliation of carbon atom positions $\mathrm{C}^{1-10}$ see the inset in Fig. 1

\begin{tabular}{|c|c|c|c|c|c|}
\hline & \multicolumn{2}{|c|}{$\underline{[\mathrm{EMIm}] \mathrm{Tf}_{2} \mathrm{~N}}$} & \multicolumn{2}{|c|}{$[\mathrm{OMIm}] \mathrm{Tf}_{2} \mathrm{~N}$} & \multirow{2}{*}{$\frac{[\mathrm{OMIm}]^{+}}{\text {Calculated }}$} \\
\hline & Calculated & Experiment & Calculated & Experiment & \\
\hline $\mathrm{N}^{\mathrm{Tf} 2 \mathrm{~N}}$ & $399.70^{\#}$ & $399.7^{\#}$ & $399.70^{\#}$ & $399.7^{\#}$ & - \\
\hline \multirow[t]{2}{*}{$\mathrm{N}^{\mathrm{Im}}$} & 403.54 & 402.3 & 403.48 & 402.4 & 403.50 \\
\hline & 403.44 & & $403.35^{\S}$ & & $403.35^{\$}$ \\
\hline \multirow[t]{2}{*}{$\mathrm{C}^{\mathrm{Tf2N}}$} & 290.84 & 293.2 & 290.76 & 293.2 & - \\
\hline & 290.75 & & 290.73 & & \\
\hline $\mathrm{C}^{1}$ & 287.24 & 287.8 & 287.16 & 287.8 & 287.53 \\
\hline \multirow[t]{2}{*}{$\mathrm{C}^{2}$} & 286.53 & 287.2 & 286.44 & 287.1 & 286.19 \\
\hline & 286.50 & & 286.42 & & 286.16 \\
\hline \multirow[t]{2}{*}{$C^{3}$} & 285.98 & 286.7 & 285.80 & 286.7 & 285.94 \\
\hline & 285.84 & & 285.75 & & 285.76 \\
\hline $\mathrm{C}^{4}$ & 284.37 & 285.6 & 284.25 & 285.2 & 283.91 \\
\hline$C^{5}$ & & & 283.77 & & 283.15 \\
\hline $\mathrm{C}^{6}$ & & & 283.56 & & 282.56 \\
\hline $\mathrm{C}^{7}$ & & & 283.43 & & 282.11 \\
\hline $\mathrm{C}^{8}$ & & & 283.40 & & 281.79 \\
\hline $\mathrm{C}^{9}$ & & & 283.37 & & 281.61 \\
\hline$C^{10}$ & & & 283.21 & & 281.26 \\
\hline
\end{tabular}

atoms in the imidazolium cation. The split between the latter two, which belongs to the two almost equivalent nitrogen positions within the imidazolium-ring, cannot be resolved in the experiment but results in the measured peak area ratio of $1: 2$ between the anion and the cation. Notably, the calculated splitting between $\mathrm{N} 1 \mathrm{~s}$ peaks related to the $\left[\mathrm{Tf}_{2} \mathrm{~N}\right]^{-}$anion $\left(\mathrm{N}^{\mathrm{Tf2N}}\right)$ and to the imidazolium cation $\left(\mathrm{N}^{\mathrm{Im}}\right)$ is about $1.1 \mathrm{eV}$ higher than found in the experiment. ${ }^{1,27,57} \mathrm{We}$ will come back to this point later in the discussion of the $\mathrm{C} 1 \mathrm{~s}$ core levels and the valence band states.

For C1s core levels the analysis of the pDOS is a little more complex. Similar to the case of the two N1s peaks, we see three well separated groups of states $\left(\mathrm{C}^{\mathrm{Tf} 2 \mathrm{~N}}, \mathrm{C}^{1 \ldots 3}\right.$, and $\left.\mathrm{C}^{4 \ldots n}\right)$ in our calculation (see Table 1 and Fig. 1): two states can be easily attributed to the carbon atoms in the $\left[\mathrm{Tf}_{2} \mathrm{~N}\right]^{-}$anion $\left(\mathrm{C}^{\mathrm{Tf} 2 \mathrm{~N}}\right)$, which form the first peak at $290.75 \mathrm{eV}(293.2 \mathrm{eV}$ in the experimental XPS spectrum ${ }^{1}$; all values given for [OMIm] $\mathrm{Tf}_{2} \mathrm{~N}$ ). Consequently, all other $\mathrm{C} 1 \mathrm{~s}$ states belong to the imidazolium cation $\left(\mathrm{C}^{1}-\mathrm{C}^{10}\right)$. They are grouped into two further peaks: those in the remaining alkyl-chain $\left(\mathrm{C}^{4}-\mathrm{C}^{10}\right)$, which contribute to the peak at $283.52 \mathrm{eV}\left(285.2 \mathrm{eV}\right.$ in the experiment $\left.{ }^{1,27}\right)$, and carbon atoms directly attached to nitrogen atoms in the imidazoliumring $\left(C^{1}-C^{3}\right)$, which give rise to the second peak at $286.23 \mathrm{eV}$ ( $286.9 \mathrm{eV}$ in the experiment ${ }^{1}$ ). Notably, the calculated contributions of the carbon atoms $\mathrm{C}^{1}-\mathrm{C}^{3}$ (see Fig. 1 and calculated binding energies in Table 1) can be exactly related to three subbands in the second peak, as recently revealed by our deconvolution of the XPS spectrum in the $\mathrm{C} 1 \mathrm{~s}$ region (see experimental binding energies from ref. 1 in Table 1). The energetic position is determined by the proximity to the nitrogen atoms and is supported by the following facts: the single $\mathrm{C}^{1}$ position, which is neighbored by two nitrogen atoms, results in the lowest intensity subband with the highest binding energy. The $\mathrm{C}^{3}$ positions each neighbored only by one nitrogen atom take the low binding energy wing and the $\mathrm{C}^{2}$ positions with one directly neighbored and another next-neighbored nitrogen atom take the middle. For the $\mathrm{C}^{2}$ and $\mathrm{C}^{3}$ positions, there remains a little uncertainty since both have the same intensity. Nevertheless, we find our attribution due to our calculations more reasonable. Furthermore, it is supported in several experimental studies. $1,57,58$

In this respect one may also argue that, since the shift of the second relative to the third peak in the experimental XPS spectrum depends strongly on the kind of anion as shown by T. Cremer et al., ${ }^{27}$ it might be possible that not the nitrogen but a site-specific binding of the anion determines the variation of the chemical shifts of the $\mathrm{C} 1$ s core levels for different carbon positions in the cation. This alternative we have checked by calculating the pDOS for a single $[\mathrm{OMIm}]^{+}$cation without any anion (see Table 1, right most column). Although the absolute energy values are slightly different, we found the same energetic order of the $\mathrm{C} 1 \mathrm{~s}$ core levels attributed to the carbon atoms $\mathrm{C}^{1}-\mathrm{C}^{10}$ for the single cation as for the [OMIm] $\mathrm{Tf}_{2} \mathrm{~N}$ ion pair. This fact points to a strong influence of nitrogen proximity rather than the anion position. Notably, the $\mathrm{C} 1 \mathrm{~s}$ binding energies of the alkyl-carbons $\left(\mathrm{C}^{4}-\mathrm{C}^{10}\right)$ depend more on the mean distance between the carbon and the two nitrogen atoms - the closer the carbon to the nitrogen the higher the $\mathrm{C}$ 1s binding energy - than on the typical distinction between aromatic and aliphatic carbon positions. Interestingly this effect propagates through the whole alkyl-chain (see Table 1, calculated binding energies for $\mathrm{C}^{4}-\mathrm{C}^{10}$ in [OMIm] $\mathrm{Tf}_{2} \mathrm{~N}$ ). In the experimental spectra this effect is indicated by a shift of the respective peak with the increasing length of the alkyl-chain. ${ }^{1,27,57}$

Finally, we have to note that like for the N1s core levels the calculated energy difference between the $\mathrm{C} 1 \mathrm{~s}$ peaks attributed to the $\left[\mathrm{Tf}_{2} \mathrm{~N}\right]^{-}$anion and the alkyl-chain of the cation is about $0.8 \mathrm{eV}$ smaller than that found in the experiment (see Table 1) for $[\mathrm{OMIm}] \mathrm{Tf}_{2} \mathrm{~N}$, whereas it is about $1.1 \mathrm{eV}$ for $[\mathrm{EMIm}] \mathrm{Tf}_{2} \mathrm{~N}$. Including both $\mathrm{N} 1 \mathrm{~s}$ and $\mathrm{C} 1 \mathrm{~s}$ core levels, this may mean that all contributions from the imidazolium cation have to be shifted by approximately $1.1 \mathrm{eV}$ to lower binding energies relatively to those from the $\left[\mathrm{Tf}_{2} \mathrm{~N}\right]^{-}$anion. Considering this fact, we are able to attribute each relevant nitrogen and carbon position to a certain feature in the N1s and C1s region of the XPS spectrum, respectively. This shift is assumed in all following reconstructed spectra.

\section{XPS valence band spectra}

In the valence band region the pDOS and, consequently, the reconstruction of XPS and UPS spectra are more entangled. The main reason is the energetic overlap of the $2 \mathrm{~s}$ and $2 p$ valence states for the elements carbon, nitrogen, oxygen, and fluorine, as well as the $3 \mathrm{~s}$ and $3 \mathrm{p}$ orbitals of sulfur. Nevertheless, following the way described in Section 2, we are able to identify the origins of the most apparent peaks in the photoemission spectra (Fig. 2, top). For this purpose we have decomposed the reconstructed XPS spectra not only into contributions of anions and cations (Fig. 2, top) but also into the contained elements (Fig. 2, bottom). In general, we find that the XPS spectrum near to the band edge is dominated by the anion contributions. 
The peak of lowest binding energy of about $7 \mathrm{eV}$ originates mainly from the contributions of oxygen with some additions nearly equally from fluorine, sulfur, and carbon. For the carbon contribution the difference between the cations [OMIm] ${ }^{+}$and [EMIm] $^{+}$expected due to the enhanced number of carbons within the alkyl-chain is minor. The peak at about $11 \mathrm{eV}$ is dominated by fluorine, oxygen and sulfur, whereas the contributions from carbon and nitrogen are negligible. A significant shoulder recognizable at the higher binding energy site of this peak can be attributed to the sulfonyl-groups of the anion. All these effects result from the fact that the cross sections for $2 p$ orbitals of nitrogen and carbon, which are the constituents of the imidazolium cations, are significantly smaller than those for the other elements. The respective cross section ratios are $3: 9: 75: 268: 777: 1252$ (H1s : C2p : N2p : O2p : F2p : S3p). Contributions from hydrogen are negligible. For the dominant contribution of the anion, the shift of cation versus anion contributions of $1.1 \mathrm{eV}$ which we applied due to the result of the core level analysis (see above and ref. 8 and 32) seems to be more or less arbitrary. It does, however, slightly improve the overlap between reconstructed and experimental spectra. For binding energies above $14 \mathrm{eV}$, contributions of nitrogen and carbon become substantial due to the higher cross sections of their $2 \mathrm{~s}$ orbitals. Nevertheless, fluorine contributions are even then still dominant. Unfortunately, in this region the experimental XPS spectra are already affected by a background of inelastic scattered electrons. Therefore, the significant deviations between the reconstructed XPS spectra of [EMIm] $\mathrm{Tf}_{2} \mathrm{~N}$ and $[\mathrm{OMIm}] \mathrm{Tf}_{2} \mathrm{~N}$ in this region could hardly be seen in the experiment (Fig. 2, left and right, respectively). The density of states (DOS), which is using the identical scaling factor and two shifts (absolute and relative between the ions) as applied for the reconstructed valence band spectra-but disregarding the MO specific cross sections, has been displayed for both ionic liquids in comparison to the reconstructed spectra (Fig. 2, top). The technique in the present study enables a quantitative analysis (reconstructed spectra) instead of a qualitative (DOS), which is an eye-catching improvement of the method.

\section{UPS spectra}

In contrast to the XPS spectra the reconstructed UPS spectra for excitation by the He II (see Fig. 3) additionally show significant contributions of carbon and nitrogen near the band edge. This results from the fact that the ratios of the cross

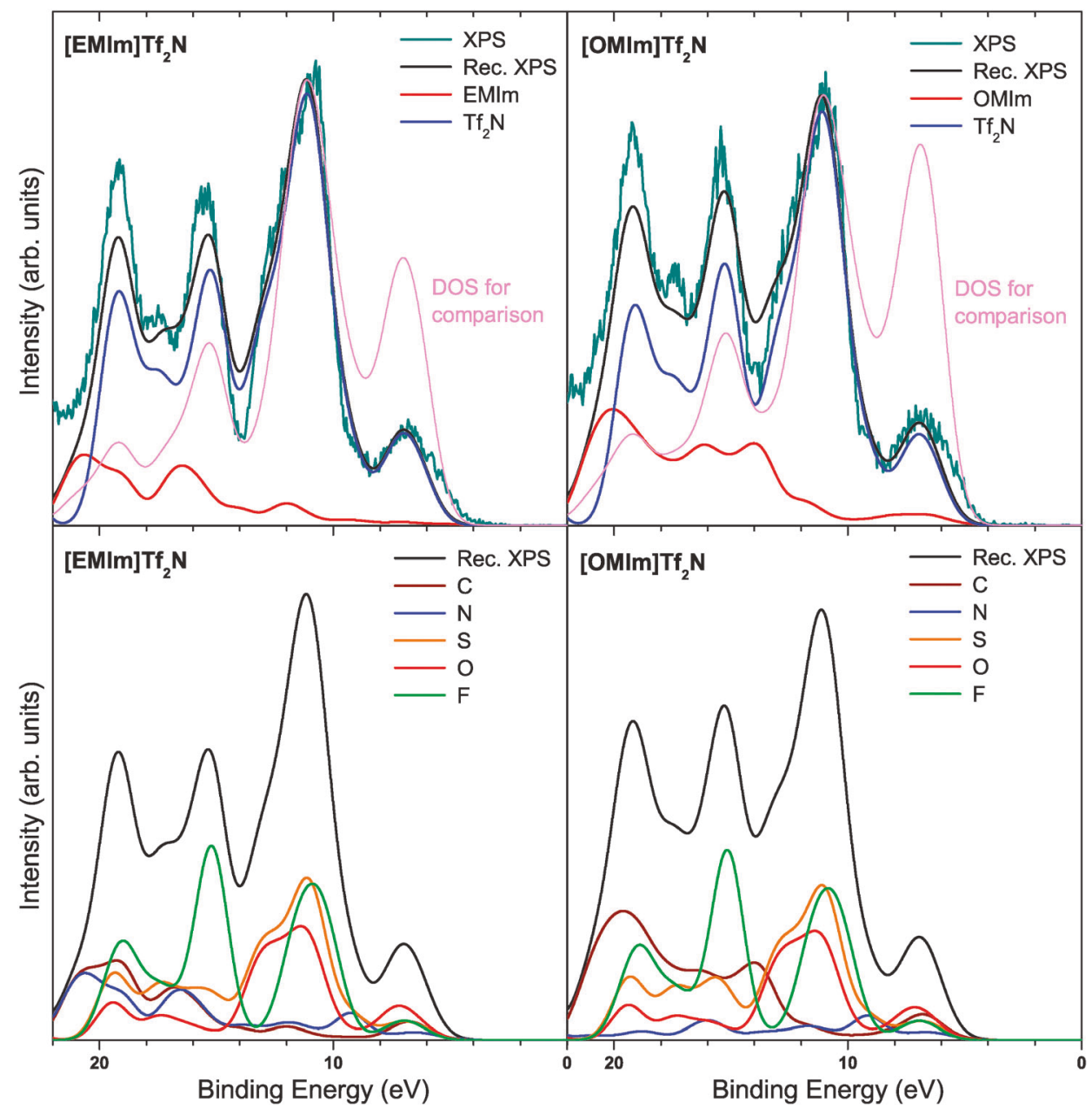

Fig. 2 Experimental (top, cyan line, from ref. 1) and reconstructed (black line) XPS spectra for the valence band of [EMIm]Tf ${ }_{2} \mathrm{~N}$ (left) and [OMIm] $\mathrm{Tf}_{2} \mathrm{~N}$ (right), with decomposition into contributions of anions (top, blue line) and cations (top, red line), as well as of the corresponding elements (bottom). The density of states (DOS) for both ionic liquids is displayed for comparison (top, purple line). 
sections between H1s : C2p : N2p : O2p : F2p : S3p orbitals at lower photon energies are turned into $2: 14: 34: 54: 69: 6$. Nevertheless, the $\left[\mathrm{Tf}_{2} \mathrm{~N}\right]^{-}$anion with fluorine and oxygen still dominate the spectra, though the strong contribution of sulfur seen in XPS has changed to nearly nothing in UPS.

For the cations the contributions of the alkyl-chains are clearly seen. In particular the difference between the corresponding [OMIm] $\mathrm{Tf}_{2} \mathrm{~N}$ and [EMIm] $\mathrm{Tf}_{2} \mathrm{~N}$ spectra (see Fig. 4), which have been normalized for $11.1 \mathrm{eV}$ to the peak maximum of the respective reconstructed UPS spectra, is apparent. By comparison with the element- and site-sensitive reconstruction of the UPS spectra, we found that the difference spectrum, which spans from $5 \mathrm{eV}$ to $12 \mathrm{eV}$, results from the additional part of the octyl-chain. This includes the carbon atoms $\mathrm{C}^{4}-\mathrm{C}^{9}$ and their respective hydrogens (brown line in Fig. 4), which are present in the $[\mathrm{OMIm}]^{+}$cation but not in the $[\mathrm{EMIm}]^{+}$ cation $\left(\mathrm{C}^{4}\right.$ in $[\mathrm{EMIm}]^{+}$corresponds to $\mathrm{C}^{10}$ in $[\mathrm{OMIm}]^{+}$for both being in a $\mathrm{CH}_{3}$-group). Remarkably, the experimental difference spectrum is about a factor 1.9 higher in intensity than the reconstructed one. This may result from the fact that due to the surface sensitivity, UPS (He II) already reveals two different surface structures for $[\mathrm{OMIm}] \mathrm{Tf}_{2} \mathrm{~N}$ and $[\mathrm{EMIm}] \mathrm{Tf}_{2} \mathrm{~N}$.
Since the octyl-chains of the $[\mathrm{OMIm}]^{+}$cations are sticking out of the surface (as shown by ref. 6, 26, 27, and 35-37), their contributions should be enhanced. Unfortunately, for a quantitative comparison of the UPS spectra, which might reveal an exact stoichiometric depth profile of the respective ionic liquid surfaces ( $c f$. ref. 36), the present state of our technique is not sufficient. In this context valuable information can be obtained from the results of the even more surface sensitive MIES method, which will be discussed in what follows.

\section{MIES spectra}

The analysis of the calculated pDOS in combination with the MIES method enables us to analyze the structure of the uppermost layer of the ionic liquid surface. For both [EMIm] $\mathrm{Tf}_{2} \mathrm{~N}$ and $[\mathrm{OMIm}] \mathrm{Tf}_{2} \mathrm{~N}$, we found contributions related to the imidazolium cation and the $\left[\mathrm{Tf}_{2} \mathrm{~N}\right]^{-}$anion. The measured spectra as well as the presence of both ions at the surface are in good agreement with the MIES study by T. Iwahashi et al. ${ }^{39}$ By subtracting the MIES spectra of $[E M I m] \mathrm{Tf}_{2} \mathrm{~N}$ from [OMIm] $\mathrm{Tf}_{2} \mathrm{~N}$ (Fig. 4, right, blue curve), we found a substantial difference for binding energies between $6 \mathrm{eV}$ and $10 \mathrm{eV}$ like in

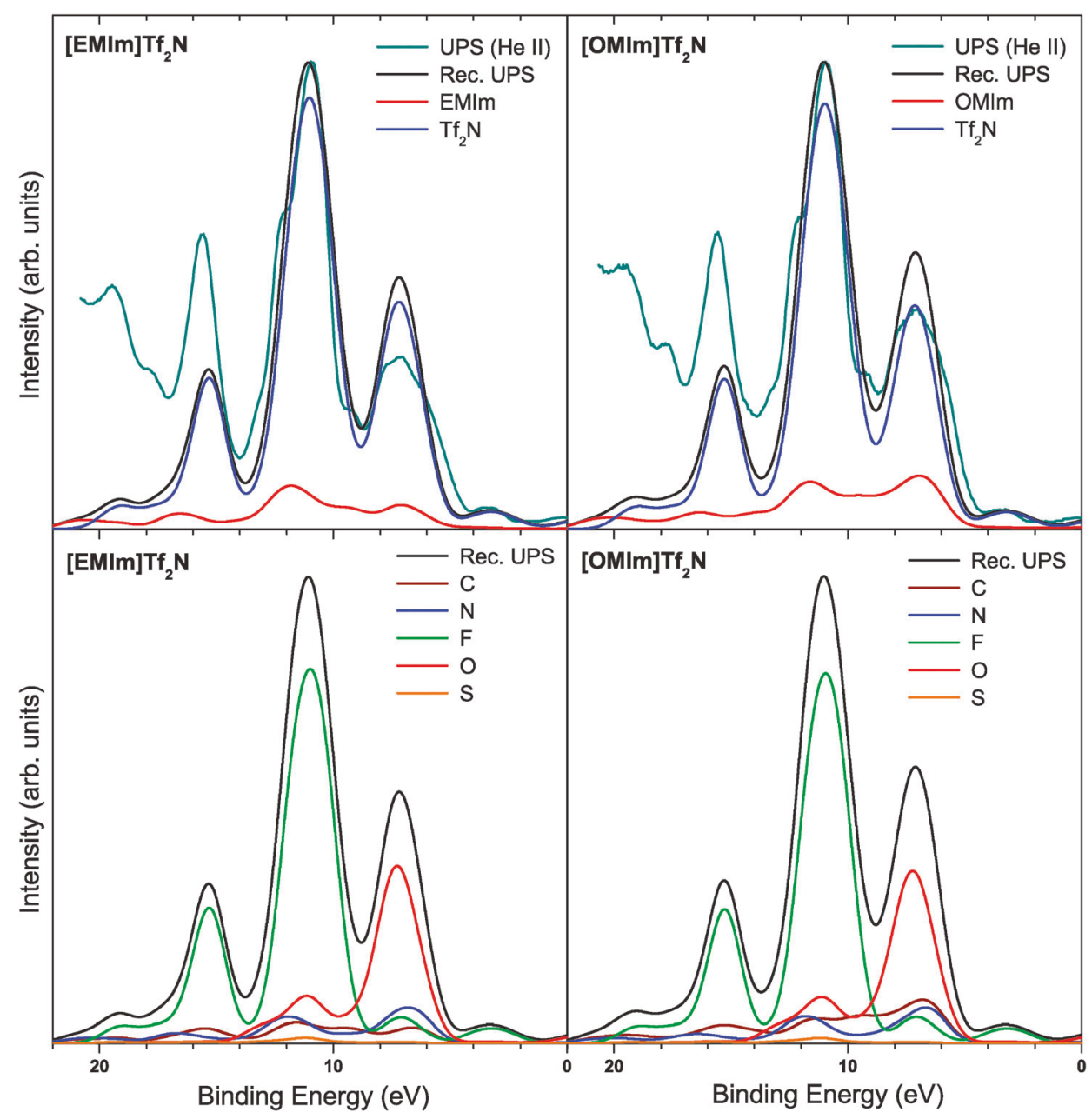

Fig. 3 Experimental (top, cyan line, from ref. 1) and reconstructed (black line) UPS (He II) spectra for the valence band of [EMIm]Tf ${ }_{2} \mathrm{~N}$ (left) and [OMIm] $\mathrm{Tf}_{2} \mathrm{~N}$ (right), with decomposition into contributions of anions (top, blue line) and cations (top, red line), as well as of the corresponding elements (bottom). 


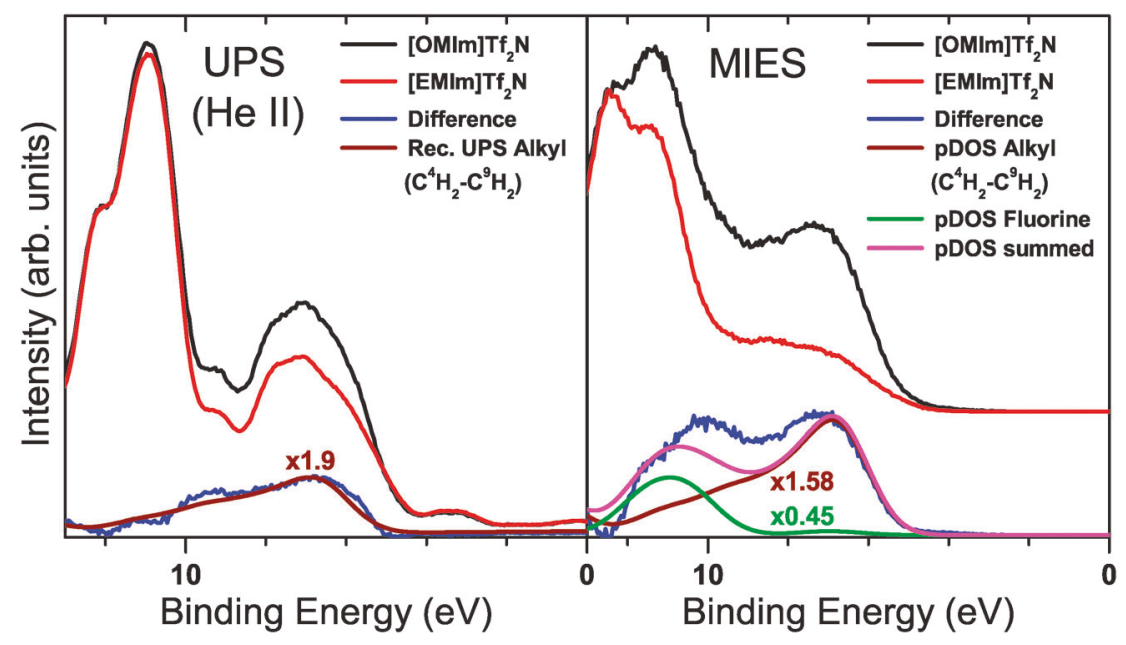

Fig. 4 Difference (blue) between the experimental UPS (left) and MIES (right) spectra of [OMIm]Tf ${ }_{2} \mathrm{~N}$ (black) and [EMIm]Tf ${ }_{2} \mathrm{~N}$ (red). For UPS (He II) these are compared with the reconstructed contributions of the alkyl-chain (brown) including the carbon atoms $\mathrm{C}^{4}-\mathrm{C}^{9}$ (see the inset in Fig. 1) and their respective hydrogens of the [OMIm] ${ }^{+}$cation (shifted by $1.1 \mathrm{eV}$ to lower binding energies and enlarged by a factor 1.9 for UPS (He II) in intensity). The MIES difference spectrum (right) is compared to contributions to the DOS of the alkyl-chain (shifted in binding energy by $-1.1 \mathrm{eV}$ ) and fluorines (green) are weighted in the ratio $7: 2$, and summed (purple).

the UPS spectra (see above and Fig. 4). This corresponds very well to the contributions from the alkyl-chain belonging to the carbon atoms $\mathrm{C}^{4}-\mathrm{C}^{9}$ and the respective hydrogen atoms (Fig. 4, right, brown curve). These are present in the [OMIm] $]^{+}$ but not in the $[\mathrm{EMIm}]^{+}$cation. Again a shift of $1.1 \mathrm{eV}$ between the cation and the anion is necessary to fit the expected alkylchain contribution to the lower binding energy edge of the difference spectrum. Due to the very high surface sensitivity of MIES this feature of the difference spectrum means that the octyl-chains of the [OMIm] ${ }^{+}$cations are present at the outermost part of the surface - a result that agrees well with our UPS (He II) reconstruction and the results from angle resolved XPS, ${ }^{25,26}$ HRBS ${ }^{35,36}$ and SFG. ${ }^{6,37}$ Note that the experimental MIES spectra have been normalized to $12.5 \mathrm{eV}$, and this may influence the obtained difference spectrum. However, in contrast to the UPS (He II) spectra the MIES difference spectrum reveals also a minor contribution from the F2p orbitals (Fig. 4, green line) at $11 \mathrm{eV}$. This may be simply interpreted as more fluorine atoms present at the ionic liquid surface in the case of $[\mathrm{OMIm}] \mathrm{Tf}_{2} \mathrm{~N}$ than of $[\mathrm{EMIm}] \mathrm{Tf}_{2} \mathrm{~N}$. However, if one considers that in $[\mathrm{OMIm}] \mathrm{Tf}_{2} \mathrm{~N}-$ but not in $[\mathrm{EMIm}] \mathrm{Tf}_{2} \mathrm{~N}$ - the imidazolium-ring may be fully buried beneath the alkyl-chain, another interpretation suggests itself: the missed contributions of the octyl-covered imidazolium-groups may feign increased contributions of the fluorines of the uncovered $\left[\mathrm{Tf}_{2} \mathrm{~N}\right]^{-}$anions. Notably, this interpretation, which is in our favor, is also in better agreement with the model of the surface structure given by K. Nakajima et al. ${ }^{36}$ obtained by their HRBS experiment. Moreover it is not in contradiction to the result that one or two trifluoro-group(s) of the anion point towards the vacuum. ${ }^{36,39}$

\section{Conclusions}

Quantum-chemical calculations are a useful tool to reconstruct and analyze XPS and UPS spectra of ionic liquids in terms of the molecular structure and stoichiometry, as we have demonstrated for a specific example in this work. Furthermore, the quantum-chemically calculated pDOS provides invaluable information for analysis and interpretation of MIES spectra. For the increasing surface sensitivity from XPS over UPS to MIES, our quantum-chemically supported technique of reconstruction and analysis provides us information about the chemical composition and steric structure of ionic liquid surfaces, in full agreement with previously suggested surface structures of [EMIm] Tf ${ }_{2} \mathrm{~N}$ and $[\mathrm{OMIm}] \mathrm{Tf}_{2} \mathrm{~N}$. $^{6,25,26,35-37}$

\section{Acknowledgements}

This study is supported by the Deutsche Forschungsgemeinschaft (DFG) Priority Program SPP 1191 "Ionic Liquids" (Kri2228/5 and En370/16-2) and by the Institute of National Colleges of Technology, Japan, which granted T. Ikari an overseas research scholarship in Ilmenau and Clausthal.

\section{References}

1 T. Ikari, A. Keppler, M. Reinmöller, W. J. D. Beenken, S. Krischok, M. Marschewski, W. Maus-Friedrichs, O. Höfft and F. Endres, e-J. Surf. Sci. Nanotechnol., 2010, 8, 241.

2 R. Hayes, G. G. Warr and R. Atkin, Phys. Chem. Chem. Phys., 2010, 12, 1709.

3 D. R. MacFarlane and K. R. Seddon, Aust. J. Chem., 2007, 60, 3.

4 C. Aliaga, C. S. Santos and S. Baldelli, Phys. Chem. Chem. Phys., 2007, 9, 3683.

5 H.-P. Steinrück, Surf. Sci., 2010, 604, 481.

6 C. S. Santos and S. Baldelli, Chem. Soc. Rev., 2010, 39, 2136.

7 P. Wasserscheid and T. Welton, Ionic Liquids in Synthesis, WileyVCH, Weinheim, Germany, 2nd edn, 2008.

8 D. Yoshimura, T. Yokoyama, T. Nishi, H. Ishii, R. Ozawa, H. Hamaguchi and K. Seki, J. Electron Spectrosc. Relat. Phenom., $2005, \mathbf{1 4 4}, 319$.

9 K. Binnemans, Chem. Rev., 2005, 105, 4148.

10 P. Wasserscheid and W. Keim, Angew. Chem., 2000, 112, 3926.

11 H. Sakaebe, H. Matsumoto and K. Tatsumi, Electrochim. Acta, 2007, 53, 1048.

12 B. Garcia, S. Lavallée, G. Perron, C. Michot and M. Armant, Electrochim. Acta, 2004, 49, 4583.

13 F. Endres and S. Z. El Abedin, Phys. Chem. Chem. Phys., 2006, 8, 2101.

14 C. Pinilla, M. G. Del Pópolo, R. M. Lynden-Bell and J. Kohanoff, J. Phys. Chem. B, 2005, 109, 17922. 
15 H. Valencia, M. Kohyama, S. Tanaka and H. Matsumoto, Phys. Rev. B: Condens. Matter, 2008, 78, 205402.

16 N. V. Plechkova and K. R. Seddon, Chem. Soc. Rev., 2008, 37, 123. 17 I. Minami, Molecules, 2009, 14, 2286.

18 A. E. Jiménez and M. D. Bermúdez, Tribol. Lett., 2010, 37, 431.

19 Q. Lu, H. Wang, C. Ye, W. Liu and Q. Xue, Tribol. Int., 2004, $37,547$.

20 J. D. Wadhawan, U. Schröder, A. Neudeck, S. J. Wilkins, R. G. Compton, F. Marken, C. S. Consorti, R. F. de Souza and J. Dupont, J. Electroanal. Chem., 2000, 493, 75.

21 S. Z. El Abedin, U. Welz-Biermann and F. Endres, Electrochem. Commun., 2005, 7, 941.

22 M. Brettholle, O. Höfft, L. Klarhöfer, S. Mathes, W. Maus-Friedrichs, S. Z. El Abedin, S. Krischok, J. Janek and F. Endres, Phys. Chem. Chem. Phys., 2010, 12, 1750.

23 A. Riisager, B. Jørgensen, P. Wasserscheid and R. Fehrmann, Chem. Commun., 2006, 994.

24 R. Ratti, S. Kaur, M. Vaultier and V. Singh, Catal. Commun., 2010, 11, 503 .

25 K. R. J. Lovelock, C. Kolbeck, T. Cremer, N. Paape, P. S. Schulz, P. Wasserscheid, F. Maier and H.-P. Steinrück, J. Phys. Chem. B, 2009, 113, 2854.

26 C. Kolbeck, T. Cremer, K. R. J. Lovelock, N. Paape, P. S. Schulz, P. Wasserscheid, F. Maier and H.-P. Steinrück, J. Phys. Chem. B, 2009, 113, 8682.

27 T. Cremer, C. Kolbeck, K. R. J. Lovelock, N. Paape, R. Wölfel, P. S. Schulz, P. Wasserscheid, H. Weber, J. Thar, B. Kirchner, F. Maier and H.-P. Steinrück, Chem.-Eur. J., 2010, 16, 8929.

28 V. Lockett, R. Sedev, C. Bassell and J. Ralston, Phys. Chem. Chem. Phys., 2008, 10, 1330.

29 E. F. Smith, F. J. M. Rutten, I. J. Villar-Garcia, D. Briggs and P. Licence, Langmuir, 2006, 22, 9386.

30 S. Krischok, R. Öttking, W. J. D. Beenken, M. Himmerlich, P. Lorenz, O. Höfft, S. Bahr, V. Kempter and J. A. Schaefer, Z. Phys. Chem., 2006, 220, 1407.

31 K. Kanai, T. Nishi, T. Iwahashi, Y. Ouchi, K. Seki, Y. Harada and S. Shin, J. Electron Spectrosc. Relat. Phenom., 2009, 174, 110.

32 K. Kanai, T. Nishi, T. Iwahashi, Y. Ouchi, K. Seki, Y. Harada and S. Shin, J. Chem. Phys., 2008, 129, 224507.

33 J. Günster, O. Höfft, S. Krischok and R. Souda, Surf. Sci., 2008, 602, 3403.

34 A. Tolstogouzov, U. Bardi, O. Nishikawa and M. Taniguchi, Int. J. Mass Spectrom., 2009, 281, 37.

35 H. Hashimoto, A. Ohno, K. Nakajima, M. Suzuki, H. Tsuji and K. Kimura, Surf. Sci., 2010, 604, 464.

36 K. Nakajima, A. Ohno, H. Hashimoto, M. Suzuki and K. Kimura, J. Chem. Phys., 2010, 133, 044702.

37 S. Baldelli, J. Phys. Chem. B, 2003, 107, 6148.

38 J. G. Huddleston, A. E. Visser, W. M. Reichert, H. D. Willauer, G. A. Broker and R. D. Rogers, Green Chem., 2001, 3, 156

39 T. Iwahashi, T. Nishi, H. Yamane, T. Miyamae, K. Kanai, K. Seki, D. Kim and Y. Ouchi, J. Phys. Chem. C, 2009, 113, 19237.

40 A. S. Pensado, P. Malfreyt and A. A. H. Pádau, J. Phys. Chem. B, 2009, 113, 14708.

41 T. Yan, S. Li, W. Jiang, X. Gao, B. Xiang and G. A. Voth, J. Phys. Chem. B, 2006, 110, 1800.

42 C. D. Wick, T.-M. Chang and L. X. Dang, J. Phys. Chem. B, 2010, 114, 14965.

43 A. D. Becke, J. Chem. Phys., 1993, 98, 5648.

44 A. D. Becke, Phys. Rev. A, 1988, 38, 3098.

45 G. Lee, W. Yang and R. G. Parr, Phys. Rev. B: Condens. Matter, 1988, 37, 785.

46 B. Miehlich, A. Savin, H. Stoll and H. Preuss, Chem. Phys. Lett., 1989, 157, 200.

47 M. J. Frisch, G. W. Trucks, H. B. Schlegel, G. E. Scuseria, M. A. Robb, J. R. Cheeseman, J. A. Montgomery, Jr., T. Vreven,
K. N. Kudin, J. C. Burant, J. M. Millam, S. S. Iyengar, J. Tomasi, V. Barone, B. Mennucci, M. Cossi, G. Scalmani, N. Rega, G. A. Petersson, H. Nakatsuji, M. Hada, M. Ehara, K. Toyota, R. Fukuda, J. Hasegawa, M. Ishida, T. Nakajima, Y. Honda, O. Kitao, H. Nakai, M. Klene, X. Li, J. E. Knox, H. P. Hratchian, J. B. Cross, V. Bakken, C. Adamo, J. Jaramillo, R. Gomperts, R. E. Stratmann, O. Yazyev, A. J. Austin, R. Cammi, C. Pomelli, J. W. Ochterski, P. Y. Ayala, K. Morokuma, G. A. Voth, P. Salvador, J. J. Dannenberg, V. G. Zakrzewski, S. Dapprich, A. D. Daniels, M. C. Strain, O. Farkas, D. K. Malick, A. D. Rabuck, K. Raghavachari, J. B. Foresman, J. V. Ortiz, Q. Cui, A. G. Baboul, S. Clifford, J. Cioslowski, B. B. Stefanov, G. Liu, A. Liashenko, P. Piskorz, I. Komaromi, R. L. Martin, D. J. Fox, T. Keith, M. A. Al-Laham, C. Y. Peng, A. Nanayakkara, M. Challacombe, P. M. W. Gill, B. Johnson, W. Chen, M. W. Wong, C. Gonzalez and J. A. Pople, Gaussian 03, Revision C.02, Gaussian Inc., Wallingford, CT, United States of America, 2004.

48 D. Strasser, F. Goulay, M. S. Kelkar, E. J. Maginn and S. R. Leone, J. Phys. Chem. A, 2007, 111, 3191

49 T. R. Leftwich and A. V. Teplyakov, J. Electron Spectrosc. Relat. Phenom., 2009, 175, 31.

50 E. I. Izgorodina, Phys. Chem. Chem. Phys., 2011, 13, 4189.

51 S. B. C. Lehmann, M. Roatsch, M. Schöppke and B. Kirchner, Phys. Chem. Chem. Phys., 2010, 12, 7473.

52 K. Fujii, T. Fujimori, T. Takamuku, R. Kanzaki, Y. Umebayashi and S. Ishiguro, J. Phys. Chem. B, 2006, 110, 8179.

53 E. Bodo, L. Gontrani, R. Caminiti, N. V. Plechkova, K. R. Seddon and A. Triolo, J. Phys. Chem. B, 2010, 114, 16398.

54 J. J. Yeh and I. Lindau, At. Data Nucl. Data Tables, 1985, 32, 1.

55 R. F. Reilman, A. Msezane and S. T. Manson, J. Electron Spectrosc. Relat. Phenom., 1976, 8, 389.

56 D. Briggs and M. P. Seah, Practical Surface Analysis, Volume 1: Auger and X-ray Photoelectron Spectroscopy, John Wiley \& Sons, Chichester, England, 2nd edn, 1992.

57 I. J. Villar-Garcia, E. F. Smith, A. W. Taylor, F. Qiu, K. R. J. Lovelock, R. G. Jones and P. Licence, Phys. Chem. Chem. Phys., 2011, 13, 2797.

58 K. R. J. Lovelock, I. J. Villar-Garcia, F. Maier, H.-P. Steinrück and P. Licence, Chem. Rev., 2010, 110, 5158.

59 M. Sun, P. Kjellberg, W. J. D. Beenken and T. Pullerits, Chem. Phys., 2006, 327, 474.

60 J. P. Perdew and R. G. Parr, Phys. Rev. Lett., 1982, 49, 1691.

61 M. Levy, J. P. Perdew and V. Sahni, Phys. Rev. A, 1984, 30, 2745.

62 M. Levy and J. P. Perdew, Phys. Rev. B: Condens. Matter, 1997, 56, 16021.

63 P. Politzer and F. Abu-Award, Theor. Chem. Acc., 1998, 99, 83.

64 D. P. Chong, O. V. Gritsensko and E. J. Baerends, J. Chem. Phys., 2002, 116, 1760.

65 R. Stowasser and R. Hoffmann, J. Am. Chem. Soc., 1999, 121, 3414.

66 S. Hamel, P. Duffy, M. E. Casida and D. R. Salahub, J. Electron Spectrosc. Relat. Phenom., 2002, 123, 345.

67 C. G. Zhan, J. A. Nichols and D. A. Dixon, J. Phys. Chem. A, 2003, 107, 4184.

68 G. Tu, V. Carravetta, O. Vahtras and H. Ågren, J. Chem. Phys., 2007, 127, 174110.

69 P. Politzer and F. Abu-Awwad, Theor. Chem. Acc., 1998, 99, 83.

70 T. A. Koopmans, Physica, 1933, 1, 104.

71 L. Šštík, M. Ončák and P. Slavíček, Phys. Chem. Chem. Phys., 2011, 13, 11998.

72 R. F. Roberts, D. L. Allara, C. A. Pryde, D. N. E. Buchanan and N. D. Hobbins, Surf. Interface Anal., 1980, $2,5$.

73 S. Tanuma, C. J. Powell and D. R. Penn, Surf. Interface Anal., 1993, 21, 165.

74 W. Sesselmann, B. Woratschek, J. Küppers, G. Ertl and H. Haberland, Phys. Rev. B: Condens. Matter, 1987, 35, 1547. 